\title{
$\mathrm{CCTV}$ 영상 정보를 활용한 이동 로봇의 자기 위치 추정 성능 향상을 위한 연구
}

박종호 ${ }^{1}$, 전영필 ${ }^{2}$, 류지형 ${ }^{2}$, 유동현 ${ }^{2}$, 정길도 ${ }^{2,3^{*}}$

${ }^{1}$ 서남대학교 전기전자공학과, ${ }^{2}$ 전북대학교 전자공학부, ${ }^{3}$ 전북대학교 전자정보신기술연구소

\section{Research to improve the performance of self localization of mobile robot utilizing video information of CCTV}

\author{
Jong-Ho Park ${ }^{1}$, Young-Pil Jeon ${ }^{2}$, Ji-Hyoung Ryu ${ }^{2}$, Dong-Hyun Yu ${ }^{2}$ and \\ Kil-To Chong ${ }^{2,3^{*}}$ \\ ${ }^{1}$ Department of Electrical \& Electronic Engineering, Seonam University \\ ${ }^{2}$ Departmant of Electronic Engineering, Chonbuk National University \\ ${ }^{3}$ Advanced Electronics and Information Research Center, Chonbuk National University
}

요 약 실내에서 자동 감시 시스템의 상업적 활용을 위하여 이동 로봇의 자기 위치 추정 능력과 더불어 주변 환경 인지 능력 향상의 필요성이 대두되고 있으며, 기존 이동 로봇의 위치 추정 및 주변 물체 인식 방법은 일반적으로 로 봇 자체의 다종 센서들을 적극 활용하고 있다. 그러나 로봇의 센서만으로 이동 로봇의 실내에서 자기 위치 추정 문제 해결에 어려움이 있기에 본 논문에서는 건물에 이미 설치되어 구동되고 있는 CCTV 영상과 마커를 활용한 이동 로봇 의 효과적이고 향상된 자기 위치 추정 기법을 제안하고자 한다. 보다 구체적으로 설명하면 먼저 마커 인식을 수행하 는데 이는 입력 영상에서 물체 혹은 이동 로봇을 사각형으로 인지하고 이들의 꼭지점을 확인한 후 마커의 특징점을 찾아내고 이후 찾아낸 특징점에 대하여 실제 마커와 영상 관계식을 이용하여 좌표변환을 수행하고 이를 기반으로 이 동 로봇의 자기 위치 추정을 수행한다. 특히, 로봇 및 장애물 등의 정보를 $\mathrm{CCTV}$ 를 기준으로 절대 좌표값으로 환산하 기에 본 연구 결과는 실내에서 로봇의 자기 위치 추정에 매우 유용하게 활용할 수 있을 것으로 사료되고 제안한 이 동 로봇의 자기 위치 추정 기법을 검증하기 위해 실 로봇 시스템을 기반으로 동작 실험을 실시하였다.

\begin{abstract}
The indoor areas for the commercial use of automatic monitoring systems of mobile robot localization improves the cognitive abilities and the needs of the environment with this emerging and existing mobile robot localization, and object recognition methods commonly around its great sensor are leveraged. On the other hand, there is a difficulty with a problem-solving self-location estimation in indoor mobile robots using only the sensors of the robot. Therefore, in this paper, a self-position estimation method for an enhanced and effective mobile robot is proposed using a marker and CCTV video that is already installed in the building. In particular, after recognizing a square mobile robot and the object from the input image, and the vertices were confirmed, the feature points of the marker were found, and marker recognition was then performed. First, a self-position estimation of the mobile robot was performed according to the relationship of the image marker and a coordinate transformation was performed. In particular, the estimation was converted to an absolute coordinate value based on CCTV information, such as robots and obstacles. The study results can be used to make a convenient self-position estimation of the robot in the indoor areas to verify the self-position estimation method of the mobile robot. In addition, experimental operation was performed based on the actual robot system.
\end{abstract}

Key Words : External Image, Localization, Marker, Mobile Robot

본 논문은 2013년도 정부(교육과학기술부)의 재원으로 한국연구재단의 지원을 받아 수행한 연구임(No. 2013-009458)

*Corresponding Author : Kil-To Chong(Chonbuk Univ.)

Tel: +82-63-270-2478 email: kitchong@jbnu.ac.kr

Received October 17, 2013 Revised November 19, 2013 Accepted December 5, 2013 


\section{1. 서론}

현재 이동 로봇을 상업적으로 활용하는 분야 중에서 건물 등에 대한 자동 감시 시스템에 로봇을 활용하고자 하며, 많은 경우 실내 공간에서 이동 로봇에 감시자 역할 을 부여하고자 하는데 이때 필요한 것이 로봇의 정확한 자기 위치 정보와 더불어 외부에 존재하는 고정식 또는 이동식 장애물의 위치도 잘 파악하고 있어야 한다. 기존 연구에서는 이동 로봇의 자기 위치 추정을 위하여 실외 의 경우에는 GPS와 관성 항법 시스템 등을 이용하여 이 동 로봇의 자기 위치를 정확하게 추정하는 연구가 진행 되고 있지만 GPS 자체의 오차를 보정하는 연구가 추가로 수행되고 있고, 실내의 경우 GPS를 사용할 수 없기에 유 사 GPS를 이용하거나 랜드마크, 초음파 센서 등을 활용 하여 이동 로봇의 실내에서 자기 위치 추정 연구가 수행 되고 있으며 이동 로봇의 외부 정보 활용을 위해서는 여 러 종류의 센서(초음파센서, 레이저 스캐너, 적외선 센서, 카메라 센서 등)를 단일 혹은 융합하여 외부 정보 및 동 적, 정적 장애물의 위치를 추정하는 연구가 진행되고 있 다[1]. 더불어 최근에는 범죄 예방 및 여러 생활 분쟁에서 의 증거 확보 등을 위하여 실-내외 CCTV의 설치가 늘고 있는 추세이다. 우리는 이제 건물 내부는 물론 실외에서 도 CCTV를 심심치 않게 볼 수 있게 되었다. CCTV의 기 술력 발달 및 데이터 선명성을 확보하기 위한 고해상도 의 카메라를 사용하는 경우가 많아지고 있으며 대부분 건물의 관제실에서 $\mathrm{CCTV}$ 내용을 녹화하는 장비를 갖추 고 있기에 이런 기반을 이용한 방범용 이동 로봇에 관심 을 기울이고 있다. 예를 들면 삼성전자는 기존의 로봇 청 소기에 고성능 카메라를 장착하여 사용자가 집을 비우더 라도 로봇 청소기의 외부 카메라를 통하여 집안의 곳곳 을 감시할 수 있는 기능을 추가한 제품을 내놓기도 했다[2].

따라서 본 논문에서는 건물에 이미 설치되어 있는 실 내 $\mathrm{CCTV}$ 그리고 이동 로봇 및 고정 또는 이동 장애물에 부착된 마커 및 이동 로봇의 센서를 활용한 고정 혹은 이 동식 장애물 정보를 활용하여 보다 효과적으로 이동 로 봇의 자기 위치 추정과 더불어 미지의 고정 혹은 이동 장 애물 정보를 파악하고 이를 활용하여 이동 로봇의 경비 시스템에 적극 활용할 수 있다. 더불어 미지의 고정 및 이동 장애물의 위치를 추정하고 이 정보를 기반으로 보 다 스마트한 이동 로봇의 주행 및 경로 계획을 실시할 수 있는 시스템을 설계하고자 한다. 더불어 II장에서는 CCTV 마커 기반의 물체 위치 추정 시스템을 소개하고자 한다. 이는 기존 CCTV 카메라와 물체간의 상대 위치 추 정이 필수적이며 이를 위해 영상 처리 방법을 활용하여 이동 로봇 및 고정 또는 이동식 장애물의 마커 판별하는
방법을 기술하였다. III장에서는 실내에서 이동 로봇이 주행 중일 때 $\operatorname{CCTV}$ (또는 외부 고정 카메라)를 이용하여 이동 로봇의 자기 위치 추정과 장애물을 회피 주행하는 실험 결과를 소개하고 있다. 그리고 마지막으로 IV장에 서는 본 연구 결과에 대한 결론을 맺었다.

본 연구의 최대 장점은 이동 로봇의 전역 위치추정을 위해 별도의 추가 센서의 설치 없이 이미 설치되어있는 $\mathrm{CCTV}$ 를 활용하는 것으로 이동 로봇 혹은 로봇 청소기에 카메라를 탑재하고 CCTV와의 정보 교류를 통하여 실내 $\mathrm{CCTV}$ 의 음영지역 탐색 및 범죄 용의자의 탐색 및 추적 등에 활용할 수 있을 것이고 이를 통하여 건물 칩임 범죄 를 줄이고 이동 로봇 사용자의 자산 및 불의의 사고에서 인명을 보호하는데 큰 도움을 줄 수 있을 것으로 사료된다.

\section{2. 마커 기반 위치추정 시스템}

\section{1 시스템 개요}

본 연구를 위하여 구성한 전체 시스템은 Fig. 1과 같 다. 우선 건물 내에 있는 기존 고정식 CCTV가 설치되어 있고 이동 로봇은 건물의 자동 감시를 위하여 건물 내부 를 순찰하며, 기본적인 이동 경로를 가지고 있다. 그리고 이동 로봇에는 마커가 부착되어 있으며, 연구 편의상 미 지의 고정 장애물 및 이동 장애물의 경우에도 각각 다른 마커를 부착하였다. 단, 이 경우 미지의 고정 장애물 및 이동 장애물에 대한 사전 정보를 감시 이동 로봇은 알지 못한다. 따라서 실내 고정 CCTV와 감시 이동 로봇은 건 물의 관제 시스템을 활용한 통신을 이용하여 정보를 송 수신하고 있으며, 관제 시스템에서는 실내 고정 CCTV의 영상을 이용하여 감시 이동 로봇과 미지의 고정 장애물 및 이동 장애물의 위치를 추정하여 감시 이동 로봇에게 데이터를 전송하게 된다.

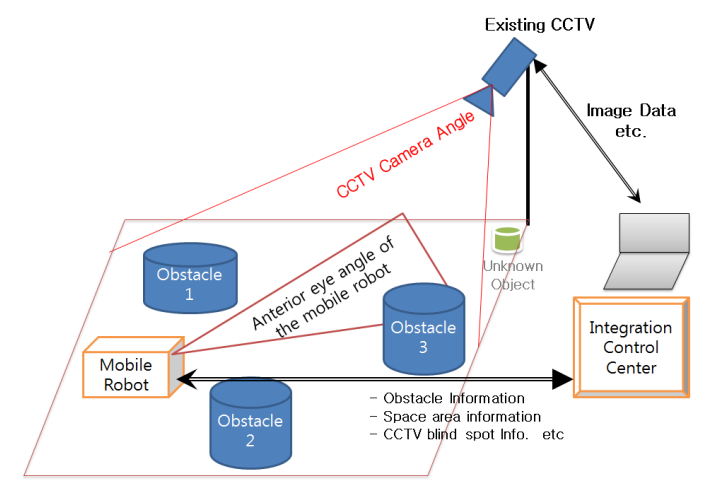

[Fig. 1] The configuration of system 
감시 이동 로봇은 Fig. 1 에서와 같이 CCTV의 음영 지 역 정보는 감시 이동 로봇 자신에게 부착된 센서를 통하 여 탐색 할 수 있으며, 관련 정보를 관제 시스템에 제공 할 수 있다. 그런데 CCTV에서 촬영한 영상으로 감시 이 동 로봇의 위치 및 미지의 고정 또는 이동 장애물을 추정 하기 위해서는 먼저 감시 이동 로봇과 실내 CCTV간의 관계를 나타내는 좌표 변환식이 필요하다[3].

\section{2 카메라와 로봇 등의 상대위치 추정}

기존 실내 $\mathrm{CCTV}$ 영상 정보 안에서의 물체는 이동 로 봇과 고정 및 이동식 장애물 등으로 분류할 수 있으며 이 에 본 연구에서는 이동 로봇에 마커를 부착하여 로봇과 장애물을 구분하게 된다. 따라서 $\mathrm{CCTV}$ 와 이동 로봇 간 에 상대적 관계를 추정하기 위해 Fig. 2와 같은 마커를 이용하며 마커에는 각 4 개의 외부, 내부 특징점이 나타난 다. 마커의 인식은 다음과 같은 순서로 이루어진다[4].

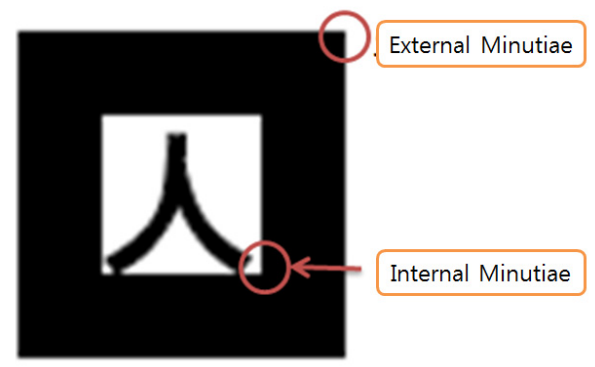

[Fig. 2] Characteristic points of marker

(1) 입력 영상을 흑백으로 전환한 후 Threshold 값을 적 용하여 이진 이미지로 만든다.

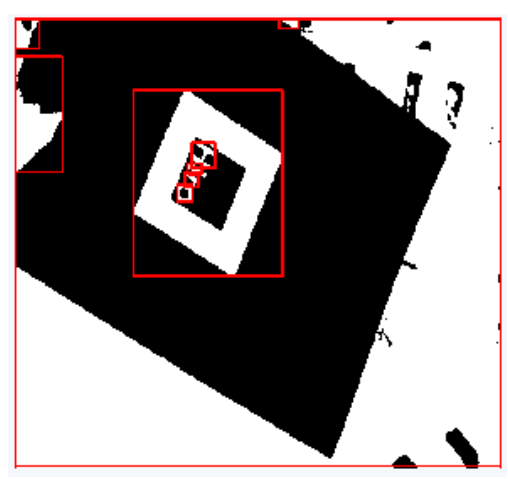

[Fig. 3] Binary image of input picture

(2) 이진 이미지 내에서 윤곽선을 골라 검은색 사각형 테두리를 인식하게 되는데 사각형 테두리 안에 다
른 사각형의 테두리를 검출하였을 경우 이를 마커 의 후보군으로 놓는다.

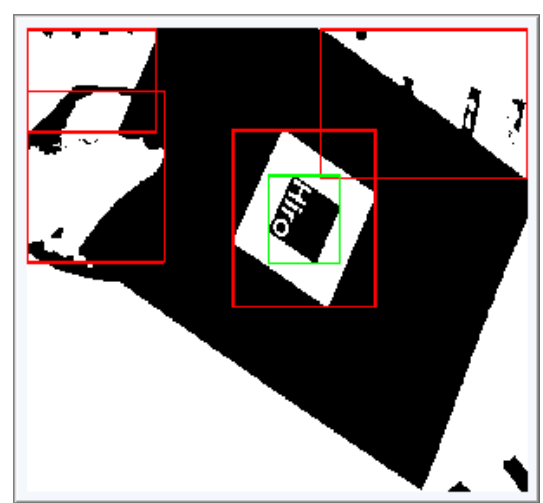

[Fig. 4] Finding candidates of the marker

(3) 찾은 후보들 중에 내부와 외부의 사각형 모양이 동 일한지 비교하여 외부사각형에서 두 대각선을 생 성하고 내부 사각형의 모서리 점이 대각선상에 배 치되면 마커의 테두리로 확정한다.

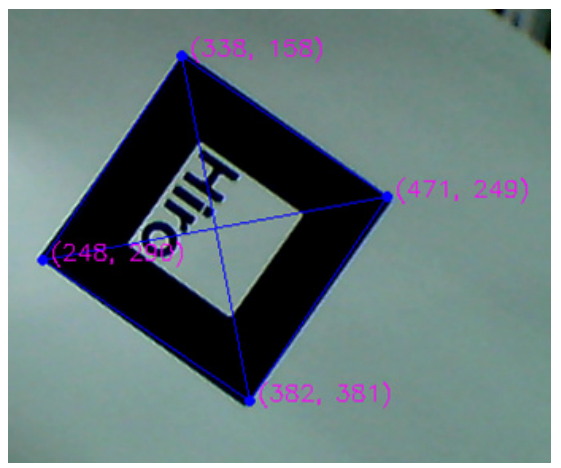

[Fig. 5] Finding diagonals and vertexs of marker

(4) 내부 사각형 내의 외곽선을 다시 추출한다.

(5) 마커 $\mathrm{DB}$ 에서 내부 사각형 내의 외곽선과 일치하는 지를 매칭하여 일치하면 마커로 인식한다.

마커의 크기와 CCTV의 카메라 내부 파라미터를 알고 있을 경우 우리는 사영기하를 이용하여 이동 로봇의 마 커와 카메라 사이의 상대적 자세, 거리 정보를 알 수 있 다[5].

따라서 CCTV 이미지와 이동 로봇의 마커간의 관계를 나타내는 식은 다음과 같다. 


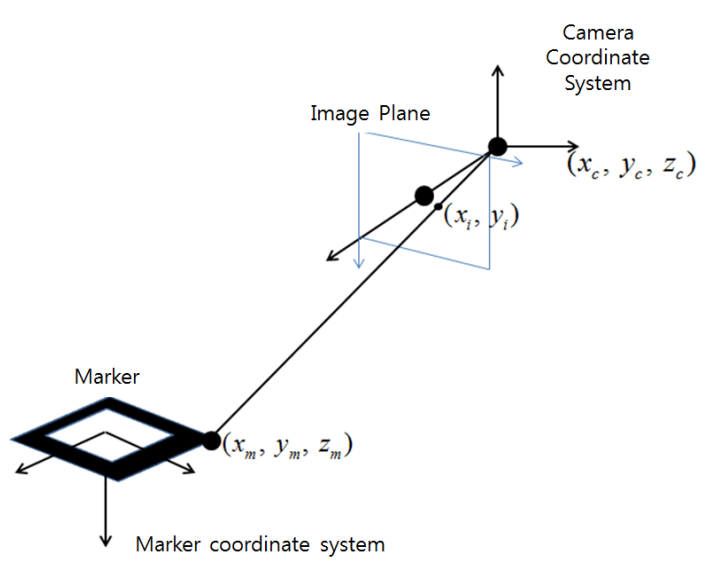

[Fig. 6] Camera and Maker coordinate

$$
\left[\begin{array}{llll}
x_{i} & y_{i} & h & 1
\end{array}\right]^{T}=P M\left[\begin{array}{llll}
x_{m} & y_{m} & z_{m} & 1
\end{array}\right]^{T}
$$

여기에서 $\left(x_{i}, y_{i}\right)$ 는 영상면에 맺힌 마커의 점이고 $\left(x_{m}, y_{m}, z_{m}\right)$ 는 마커의 3 차원 평면에서의 좌표고, $\mathrm{P}$ 는 카메라 내부 매개변수를 포함한 행렬이고, $\mathrm{M}$ 은 마커와 카메라의 상대 관계를 나타내는 행렬이다.

$P=\left[\begin{array}{cccc}s_{x} f & 0 & x_{0} & 0 \\ 0 & s_{y} f & y_{0} & 0 \\ 0 & 0 & 1 & 0 \\ 0 & 0 & 0 & 1\end{array}\right], \quad M=\left[\begin{array}{cccc}R_{11} & R_{12} & R_{13} & T_{x} \\ R_{21} & R_{22} & R_{23} & T_{y} \\ R_{31} & R_{32} & R_{33} & T_{z} \\ 0 & 0 & 0 & 1\end{array}\right]$

여기에서 $\mathrm{f}$ 는 카메라의 초점거리를 나타내고 $\left(x_{0}, y_{0}\right)$ 는 실제 카메라 좌표계의 Z축이 영상을 통과하면서 만나는 점을 나타낸다. 하지만 보통은 영상의 중심점을 사용한 다. $\mathrm{Sx}$ 는 스케일 값으로 영상의 $\mathrm{x}$ 축에서의 $\mathrm{pixel} / \mathrm{mm}$ 의 거리를 $\mathrm{Sy}$ 는 영상의 $\mathrm{y}$ 축에서의 $\mathrm{pixel} / \mathrm{mm}$ 의 거리를 나타 낸다. $\mathrm{R}$ 은 회전요소를 나타내며 $\mathrm{T}$ 는 평행이동 요소를 나 타낸다[6].

\section{3. 실험}

\section{1 실험의 구성}

본 연구 결과를 확인하기 위하여 실제 로봇을 활용한 실험의 구성은 다음 Fig. 7과 같다.

실험을 위한 전체 시스템의 구성은 먼저, $\mathrm{CCTV}$ 영상 및 이동 로봇의 센서 자료 등을 통합 제어하는 관제소를 대신해서 노트북을 이용하였고, 실내용 CCTV 대용으로
는 웹캠을 활용하였으며, 웹캠의 영상을 받아 마커와 카 메라간의 위치를 처리하였다. 웹캠은 CCTV의 역할을 하 므로 일단 고정되어 있고 지상에서 웹캠까지의 높이는 $1 \mathrm{~m}$ 로 설정하였고 웹캠이 바라보는 각도역시 고정하여 카메라좌표계에서 전역좌표계로의 좌표변환에 이용하였 다. 더불어 웹캠의 사양은 최대 $1024 \times 768$ 의 해상도를 지 원하며 15 프레임의 동영상을 전송할 수 있다.

관제소의 역할을 하는 노트북에서는 이동 로봇과의 통 신을 통해 이동 로봇의 주행 경로를 조정하거나 이동 로 봇의 원격 조정 및 수동으로 제어 할 수 있게 하였다. 이 동 로봇에는 주변의 물체 및 환경 인지를 위하여 초음파 센서와 적외선 센서가 탑재되어있다[7,8].
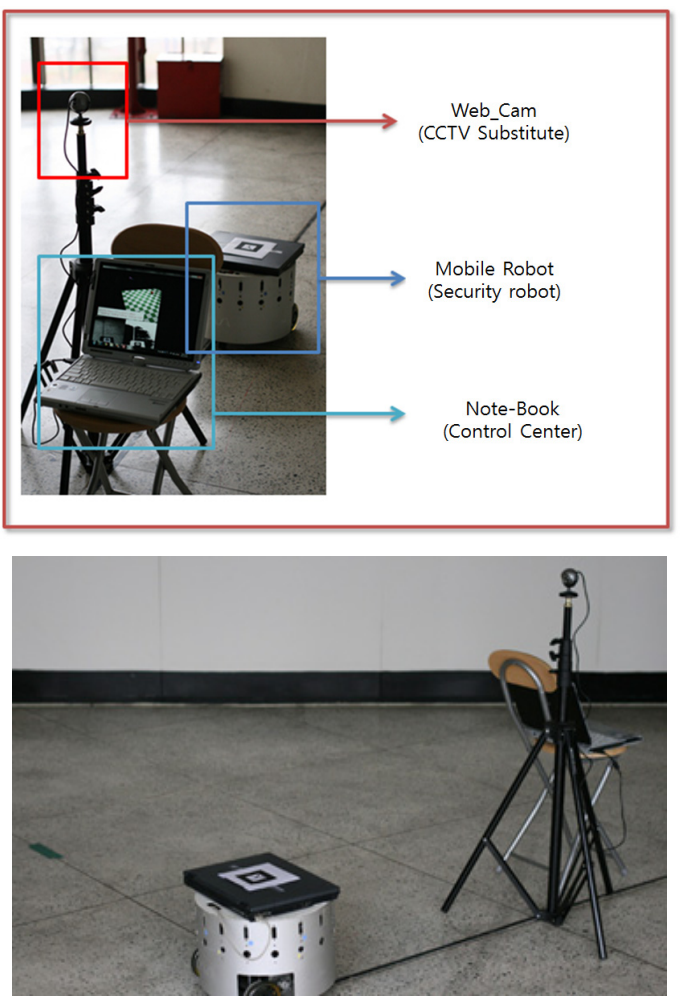

[Fig. 7] The experiment setup

\section{2 카메라 캘리브레이션}

카메라 캘리브레이션을 위해 Matlab Camera Calibration Toolbox를 사용하였다[9]. 여러 각도, 거리에 서 정해진 격자무늬를 촬영하고 영상처리를 이용하여 카 메라의 내재된 파라미터들을 알아보았다. 그 결과 Fig. 8 과 같은 카메라의 내부 파라미터를 얻을 수 있었다. 여기 에서 fc는 초점거리를 나타내며 $\mathrm{cc}$ 는 영상의 중심좌표, Skew는 이미지평면의 비뚤어짐 정도를 나타낸다. 
Distortion은 왜곡의 정도를 나타내는데 이는 렌즈의 가장 자리 부분에서 어안렌즈효과와 비슷한 효과가 나는 것을 말한다[10].
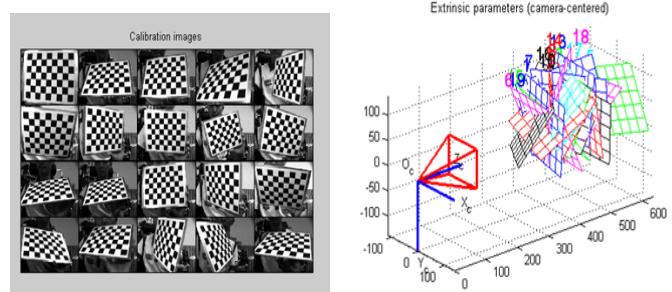

Focal Length: Principal point: Skev: IC= $=\left[\begin{array}{lll}1375.39678 & 1300.29529\end{array}\right]$ 미 $9.40693 \quad 9.79664 \mid$

Distortion:

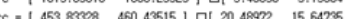

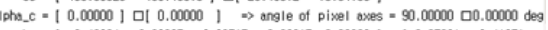

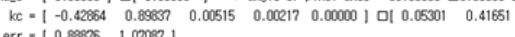

[Fig. 8] Camera calibration using Matlab.

\section{3 이동 로봇 실내 자기 위치 추정 실험}

기존 $\mathrm{CCTV}$ 영상 정보를 활용한 이동 로봇의 실내 위 치 추정 실험을 위하여 실제 이동 로봇을 $1 \mathrm{mx} 1 \mathrm{~m}$ 의 격 자 구조에서 대각선으로 이동시키면서 자기 위치를 추정 하고 있는지를 살펴보았으며 주행 경로 중에서 시작과 끝 부분에서는 이동 로봇을 회전하게 하여 이동 로봇의 자세 제어에 대한 부분 및 위치 추정을 하고 있는지도 살 펴보았다[11]. 이동 로봇의 동작 실험 결과를 분석하면 이동 로봇의 주행 시에는 비교적 안정적으로 위치를 추 정함을 보였으나 이동로봇이 회전할 때에 약 $5 \mathrm{~cm}(5 \%)$ 의 오차를 보였다. 그러나 이러한 오차는 카메라의 해상도, 마커의 크기, 주변광의 영향 등을 받아 발생하는 것으로 사료되며 충분히 좋은 연구 결과로 판단되어진다. 더불어 $5 \mathrm{~m}$ 이내에서도 약 $25 \mathrm{~cm}(5 \mathrm{~m})$ 정도의 오차를 보이고 있기 에 이동 로봇의 실내 자기 위치 추정에 있어 매우 좋은 연구 결과를 얻었음을 확인할 수 있었다.

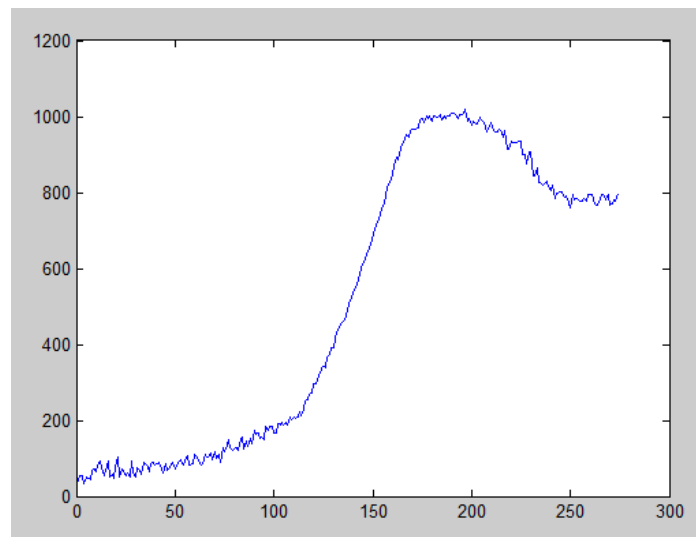

[Fig. 9] The result of estimation for $\mathrm{x}$ position

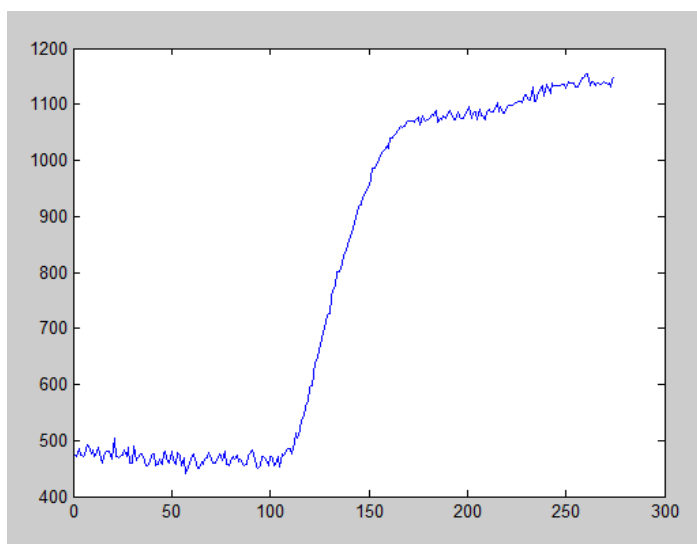

[Fig. 10] The result of estimation for $y$ position

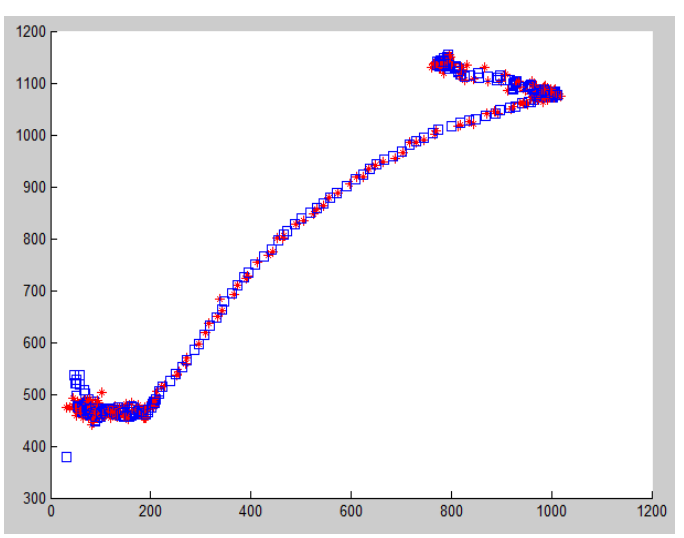

[Fig. 11] The result of localization

\section{4. 결론}

최근 우리 주변에는 건물 실·내외에 많은 CCTV가 설 치되어 있다. 특히, 도시 랜드마크 건물 또는 공공기관 등 의 주요 건물에는 물론 원룸 건물이나 일반 가정집 등에 서도 CCTV의 보급이 늘고 있는 것이 현실이다. 그러나 $\mathrm{CCTV}$ 는 한번 설치하면 이동이 불편하고 고정된 영상 시 각을 가지므로 $\mathrm{CCTV}$ 에는 필연적으로 음영지역이 존재 하게 되고 이런 음영지역을 없애기 위해서는 추가로 $\mathrm{CCTV}$ 를 설치하거나 또는 CCTV에 팬틸트 등을 부착하 거나 보조 센서 등을 활용하는 방법들이 활용되고 있는 실정이다. 이런 점은 $\mathrm{CCTV}$ 만을 이용하여 건물을 감시하 기에는 문제가 있다는 사실을 알려주고 있으며 이런 점 을 해소하고자 일환으로 최근 여러 업체에서 기존의 청 소용 로봇 등에 외부 카메라를 설치하여 활용하거나 아 니면 새로운 로봇 플랫폼을 개발하여 전문 방범용으로 사용하려는 시도가 보이고 있다. 그런데 이런 방범용 이 
동 로봇이 임무를 수행하려면 자기 주변의 장애물을 파 악하고 이동 로봇 자신의 위치를 추정하는 작업이 필요 하다.

따라서 본 논문에서는 기존에 설치된 실내 CCTV와 방법용 이동 로봇 플랫폼에 마커를 부착하여 이를 인식 하고 이동 로봇의 자기 위치 추정 정보와 더불어 경로상 에 존재하는 미지의 고정 또는 이동 장애물에 대한 정보 를 이용하여 방법용 이동 로봇의 보다 스마트한 주행 방 법을 구현하고자 한다.

더불어 물체 마커의 특징점을 파악하고 사영변환과 실 내 CCTV의 내부 파라미터를 이용한다면 물체 마커와 실 내 CCTV사이의 상대적 거리, 자세를 알 수 있다. 실내 $\mathrm{CCTV}$ 의 내부 파라미터는 캘리브레이션을 이용하여 알 수 있으며 최근에 나온 ARToolkit 증강현실 라이브러리 를 이용한다면 보다 쉽게 접근할 수 있다. 본 연구를 증 명하기 위한 실제 실험에서는 마커를 부착한 이동 로봇 의 자기 위치 추정이 얼마나 정확한지를 살펴보았다. $1 \mathrm{~m}$ $\mathrm{x} 1 \mathrm{~m}$ 이내에서 약 $5 \mathrm{~cm}$ 의 오차를 보여 실내에서의 위치 추정에 큰 무리가 없을 것으로 생각된다.

향후 이동 로봇에 장착된 각종 센서와 연계하여 장애 물 지도를 작성하고 이를 이용하여 관제실과 협력, 순찰 경로계획을 세우게 된다면 방범 순찰용 로봇으로서 좋은 성과가 있을 것으로 사료된다.

\section{References}

[1] Sebum Chun, et al, "Estimation of Precise Relative Position using INS/Vision Sensor Integrated System", Journal of the Korean Society for Aeronautical and Space Sciences, Vol.36 No.9, pp. 891-897, 2008. DOI: http://dx.doi.org/10.5139/JKSAS.2008.36.9.891

[2] http://kr.engadget.com/2011/03/15/tango-view/

[3] A. Ess, et al, "A mobile vision system for robust multi-person tracking", CVPR, pp. 1-8, IEEE, 2008. DOI: http://dx.doi.org/10.1109/CVPR.2008.4587581

[4] Jae-Kyung Lee and Young-Hwan Park, "Localization of Mobile Robot using Active Landmark", Journal of KAIS, Vol. 9, No. 1, pp. 64-69, 2008.

DOI: http://dx.doi.org/10.5762/KAIS.2008.9.1.064

[5] M.M.Y. Chang and K.H. Wong, "Model reconstruction and pose acquisition using extended Lowe's method", IEEE Transactions on Multimedia, Vol. 7, No. 2, pp. 253-260, 2005.

DOI: http://dx.doi.org/10.1109/TMM.2005.843344

[6] Sung-Ki Kwon, et al, "A Study of Compensation
Algorithm for Localization based on Equivalent Distance Rate using Estimated Location", Journal of KAIS, Vol. 11, No. 9, pp. 3571-3577, 2010.

DOI: http://dx.doi.org/10.5762/KAIS.2010.11.9.3571

[7] Ji-Hyoung Ryu, et al, "The navigation method of mobile robot using a omni-directional position detection system", Journal of KAIS, Vol. 10, No. 2, pp. 237-242, 2009.

DOI: http://dx.doi.org/10.5762/KAIS.2009.10.2.237

[8] Sung-Hwa Hong, Seok-Yong Jung, "Localization Algorithm in Wireless Sensor Networks using the Acceleration sensor", Journal of KAIS, Vol. 11, No. 4, pp. 1294-1300, 2010.

DOI: http://dx.doi.org/10.5762/KAIS.2010.11.4.1294

[9] Camera Calibration Toolbox for Matlab, http://www.vision.caltech.edu/bouguetj/calib doc/

[10] J.-Y. Park, "Experiments on vision guided docking of an autonomous underwater vehicle using one camera", Ocean Engineering, Vol. 36, No. 1, pp. 48 - e61, 2009. DOI: http://dx.doi.org/10.1016/j.oceaneng.2008.10.001

[11] Gyumin Lee, et al, "New algorithm of localization Using Odometry and RFID system", Journal of CICS, Vol. 2008, No. 10, pp. 91-92, 2008.

박 종 호(Jong-Ho Park)

[정회원]

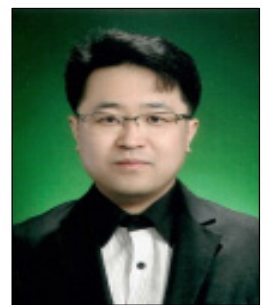

- 1999년 2월 : 전북대학교 전기공 학과 (공학석사)

- 2001년 8월 : 전북대학교 전자공 학과 (공학박사 수료)

- 2009년 3월 2010년 12월 : 전 북대학교 공과대학 시간강사

- 2011년 2월 현재 : 서남대학 교 전기전자공학과 교수

<관심분야>

로봇 제어, 임베디드 시스템, 비선형 제어 이론 등 


\section{전 영 필(Young-Pil Jeon)}

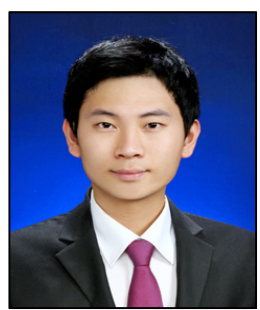

- 2013년 2월 : 전북대학교 전자정 보공학부 졸업

- 2013년 3월 현재 : 전북대학교 대학원 전자정보공학부 석사과정

<관심분야>

영상 처리, 임베디드 시스템, 위치추정 등

류 지 형(Ji-Hyoung Ryu)

[정회원]

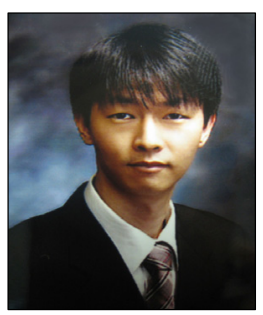

- 2005년 2월 : 전북대학교 전자정 보공학부 졸업.

- 2007년 2월 : 전북대학교 대학원 제어계측공학과 공학석사.

- 2008년 3월 현재 : 전북대학 교 대학원 전자정보공학부 박사 과정.

<관심분야>

영상 처리, 임베디드 시스템, 무인 쿼드로터 제어 등

유 동 현(Dong-Hyun $\mathrm{Yu})$

[준회원]

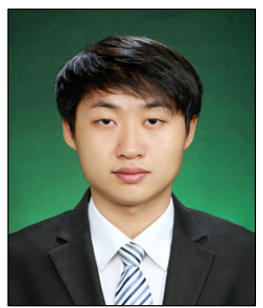

- 2012년 8월 : 군산대학교 제어로 봇공학과 졸업

- 2013년 3월 현재 : 전북대학교 대학원 전자정보공학부 석사과정
정 길 도(Kil-To Chong)

[정회원]

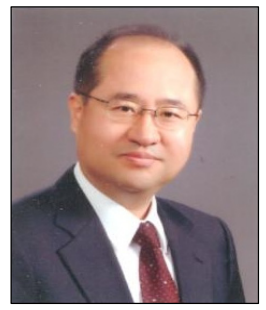

- 1984년 6월 : Oregon State University 기계공학(공학사)

- 1986년 12월 : Georgia Institute of Technology 기계공학(공학석사)

- 1992년 5월 : Texas A\&M University 기계공학 (공학박사)

- 1996년 3월 현재 : 전북대학교 전자공학부 교수 및 학부장, 전 북대 전자정보신기술연구소 소장

<관심분야>

Time-Delay, Robotics, 인공지능, 센서네트워크.

<관심분야>

이동 로봇 제어, SLAM 등 